\title{
Infantile mercury poisoning
}

INSERM

\section{Source}

INSERM. (1999). Orphanet: an online rare disease and orphan drug data base. Infantile mercury poisoning. ORPHA:247165

Infantile mercury poisoning is a rare intoxication affecting children, most commonly characterized by erythema of the hands, feet and nose, edematous, painful, pink to red, desquamating fingers and toes, bluish, cold and wet extremities, excessive sweating, irritability, photophobia, muscle weakness, diffuse hypotonia, paresthesia, hypertension and tachycardia, due to elemental, org anic or inorganic mercury exposure. Additional manifestations include alopecia, loss of appetite, excessive salivation with red and swollen gums, tooth and nail loss and insomnia. 